Referencia para citar este artículo: D’Aloisio, F. (2017). Jóvenes y sociabilidad escolar: Aprendizajes que sostienen determinado orden social. Revista Latinoamericana de Ciencias Sociales, Niñez y Juventud, 15(1), pp. 101-115.

\title{
Jóvenes y sociabilidad escolar: Aprendizajes que sostienen determinado orden social*
}

\author{
FlorenCIA D'AloISIo ** \\ Docente-Investigadora Universidad Nacional de Córdoba, Argentina.
}

\begin{abstract}
Artículo recibido en noviembre 9 de 2015; artículo aceptado en enero 19 de 2016 (Eds.)
\end{abstract}
- Resumen (descriptivo): Presentamos un recorte de una tesis doctoral finalizada que reconstruyó, situada y comparativamente, los sentidos que adquiere la secundaria para jóvenes de Córdoba (Argentina) en desiguales condiciones de vida y escolaridad. Inscripta en un enfoque sociohermenéutico, la estrategia de indagación múltiple fue implementada de forma análoga en dos poblaciones estudiantiles focalizando progresivamente en varios registros de las voces juveniles: observacionales, escritas, discusiones grupales, entrevistas profundas. Identificamos diversos núcleos de significación juvenil que comprenden a la secundaria como "espacio-tiempo de experiencias y aprendizajes" (construcción de conocimientos, sociabilidad), "preparación para futuros desempeños" (laboral, propedéutico), "formación personal" ("ser alguien digno" o "exitoso"), "ciudadanización” ("instancia des-ignorante” o "ciudadanía participativa”). En esta comunicación analizamos cómo los sentidos juveniles sobre la sociabilidad escolar se vinculan a la producción de subjetividades que sostienen determinado orden social.

Palabras clave: Jóvenes urbanos, escuela secundaria, sentidos, experiencias, aprendizajes, relaciones interpersonales (Tesauro de Educación de la Unesco-OIE).

\section{Youth and school sociability: Learnings that support a determined social order}

Abstract (descriptive): The authors present part of a finished doctoral thesis that reconstructs, in a situated and comparative manner, the meanings that secondary school has for young people in Cordoba (Argentina) who inhabit unequal living conditions and educational access. Using a socio-hermeneutical approach, the methodology involved multiple activities was implemented with two student populations, progressively focusing on collecting the voices of different young people using the following methods: observation, writing, group discussions and in-depth interviews. The authors identify different groups of the meanings created by young people to understand secondary school including a "space-time of experiences and learnings" (knowledge building, sociability), "preparing for future action" (work, university), "personal training" ("to be someone worthy" or "successful"), "citizenship" ("not being ignorant" or "participatory citizenship"). In this article the authors analyze how the youth meanings related to school sociability are related to the production of subjectivities that support a determined social order.

Este artículo de reflexión sintetiza uno de las líneas analíticas del trabajo “¿Qué es la escuela secundaria para sus jóvenes? Un estudio sobre significaciones situadas en disímiles condiciones de vida y escolaridad" presentado por la autora en marzo de 2015 para optar por el título de Doctora en Estudios Sociales de América Latina del Centro de Estudios Avanzados, Universidad Nacional de Córdoba, Argentina. La investigación desde una perspectiva sociohermenéutica fue realizada entre agosto de 2010 y diciembre de 2012 con financiamiento del Consejo Nacional de Investigaciones Científicas y Técnicas (Conicet) (Resolución D No 29/08 y No 320/11). Área de conocimiento: Ciencias Sociales Interdisciplinarias; subárea: Temas Especiales (Estudios psicosociales sobre juventud y educación).

** Licenciada en Psicología, Universidad Nacional de Córdoba (UNC). Doctora en Estudios Sociales de América Latina, Centro de Estudios Avanzados (UNC). Becaria Posdoctoral del Consejo Nacional de Investigaciones Científicas y Técnicas (Conicet) con sede en el Centro de Investigaciones de la Facultad de Filosofía y Humanidades (CIFFyH-UNC) y el Núcleo de Estudios Psicosociales y Comunitarios (Nepsico) de la Facultad de Psicología (UNC). Correo electrónico: florenciadaloisio@gmail.com 
Key words: Urban youth, secondary school, meanings, experiences, learnings, interpersonal relationships (Unesco Education Thesaurus-OIE).

\section{Juventude e sociabilidade escolar: aprendizagems que sustentam determinada ordem social}

- Resumo (descritivo): Apresentamos um recorte de uma tese de doutorado concluida que reconstruiu, localizada e comparativamente, os sentidos que adquire o ensino médio para jovens de Córdoba (Argentina) em diferentes condições de vida e educação. Baseados numa abordagem sociohermenêutica, a estratégia de indagação múltipla foi implementada de forma análoga em duas populações de estudantes numa gradual focalização dos diferentes registros das vozes juvenis: observacionais, atividades escritas, discussões grupais, entrevistas em profundidade. Identificamos diversos núcleos de significação que compreendem ensino médio como "espaço-tempo de experiências e aprendizagens" (construção de conhecimentos, sociabilidade), "preparação para o desempenho futuro" (trabalho, universidades), "formação pessoal” ("ser alguém digno" ou "bem-sucedido"), "cidadania" ("instância des-ignorante" ou "cidadania participativa"). Neste artigo analisamos como os sentidos sobre a sociabilidade escolar estão ligados à produção de subjetividades que sustentam determinada ordem social.

Palavras chave: Juventude urbana, ensino médio, significados, experiências, aprendizagems, relações interpessoais (Thesaurus da Educação da Unesco-OIE).

-1. Indagar sentidos educativos juveniles situados en disímiles condiciones vitales y escolares. -2. Enfoque de investigación y estrategias metodológicas. -3. Aprender a vivir con otros: La secundaria como espacio-tiempo de sociabilidad. -4. Reflexiones finales. -Lista de referencias.

\section{Indagar sentidos educativos juveniles situados en desiguales condiciones vitales $y$ escolares}

Este artículo se deriva de una tesis doctoral finalizada en la que reconstruimos los sentidos de la escuela secundaria desde la perspectiva de jóvenes escolarizados de la ciudad de Córdoba, Argentina.

El análisis de los datos allí construidos nos permitió indicar que jóvenes situados en condiciones desiguales de vida y escolarización comprenden a la secundaria como espaciotiempo de "experiencias y aprendizajes" (construcción de conocimientos, sociabilidad), "preparación para futuros desempeños" (laboral, propedéutico), "formación personal" ("ser alguien digno" o "exitoso") y "ciudadanización" ("instancia des-ignorante" o "ciudadanía participativa").

Compartimos en esta ocasión el análisis de los sentidos juveniles sobre la escuela secundaria como espacio-tiempo de sociabilidad. Intentaremos mostrar cómo los mismos se construyen a partir de marcos intersubjetivos de referencia, desde particulares trayectorias socioeducativas-laborales familiares, en el seno de específicos contextos institucionales y en virtud de una trayectoria biográfica virtual de cara al porvenir que los jóvenes anticipan.

La problemática objeto de nuestra investigación retoma una preocupación epocal por comprender la relación de los jóvenes con la escuela, lo que valoran y esperan de su tránsito por este nivel educativo, sus vivencias y experiencias. De ello da cuenta la existencia de una agenda regional de debates, reformas educativas, discursos sociomediáticos e investigaciones.

Al igual que en otros países latinoamericanos ${ }^{1}$, en el 2006 Argentina declaró obligatoria la educación secundaria (Ley Nacional de Educación $N^{\circ}$ 26.206), sumándose a una "obligatoriedad social" preexistente (Tenti-Fanfani, 2007). En este escenario de doble obligatoriedad, nos encontramos ante una institución sobre la que recayeron fuertes cuestionamientos, una definición legal de sus funciones en continuidad con significados consolidados a lo largo de su historia (formación

1 Perú (2003), Uruguay (2006), Venezuela (2009), Brasil (2009), Paraguay (2010), Bolivia (2010), Honduras (2012) y México (2012). 
propedéutica, instrumental y política) y la creciente incorporación de "nuevos" jóvenes para quienes no fue originalmente destinada.

Numerosos estudios latinoamericanos se abocaron a analizar la problemática del sentido de la escuela secundaria desde la mirada juvenil (Guerra-Ramírez, 2000; Guerrero-Salinas, 2000; Andrade-Glória, 2003; Ghiardo-Soto \& Dávila-León, 2005; Dos Santos, Nascimento \& Menezes, 2012; Guerra-Ramírez \& Guerrero-Salinas, 2012; Tapia-García, 2012; Weiss, 2012; Molina-Chávez, 2014). En Argentina, algunas investigaciones focalizaron en experiencias y sentidos educativos de estudiantes pertenecientes a grupos sociales específicos, denominados "populares", "empobrecidos", "excluidos" (Duschatzky \& Corea, 2007; Foglino, Falconi \& López Molina, 2008; Meo \& Dabenigno, 2010) o bien de sectores favorecidos, de élites (Del Cueto, 2007; Tiramonti, 2007; Ziegler, 2007). Otros estudios trabajaron con muestras poblacionales más extensas y heterogéneas geográfica, socioeconómica e institucionalmente (Kessler, 2002; Dussel, Brito \& Núñez, 2007; Llinás, 2009).

En nuestra mirada, los abordajes focalizados aportan análisis contextualizados de los procesos de significación juvenil, pero sus caracterizaciones quedan, muchas veces, ligadas a explicaciones de clases. Por las características de sus abordajes, los segundos se alejan, en cierta forma, de una comprensión situada contextual e institucionalmente. Concibiendo a los sujetos en su doble condición de jóvenes y estudiantes (D’Aloisio, 2015), un supuesto cada vez más considerado en las investigaciones educativas (Weiss, 2012), buscamos comprender y comparar sentidos juveniles sobre la escuela secundaria situados en condiciones desiguales de vida y escolarización.

\section{Enfoque de investigación y estrategias metodológicas}

Trabajamos desde un enfoque de indagación e interpretación sociohermenéutico desde el cual la problemática del sentido de la escuela secundaria requiere ser pensada en clave sociohistórica (Gadamer, 1992; Thompson, 1993), situada, dialógica (Bajtin,
1990; Ricœur, 1999) e interdiscursiva (Verón, $1993)^{2}$. La sociohermenéutica, en tanto quehacer reinterpretativo, busca reconstruir el sentido de los discursos en su situación micro y macro social de enunciación, atendiendo al carácter relacional, posicional y conflictivo de los mismos y ligando relacionalmente subjetividad personal, objetividad social e intersubjetividad (Alonso, 2013).

Entendemos que en las construcciones de sentido juveniles se articulan elementos estructurales (relativos a sus condiciones de vida y escolarización), aspectos intersubjetivos (experiencias y discursos de referentes significativos) y de la dimensión biográfica presente y por-venir.

Buscamos analizar las construcciones de sentido en función de sus particulares condiciones de producción y comparar sentidos ligados a condiciones desiguales de producción ${ }^{3}$ (ver tabla 1). Seleccionamos como recorte poblacional a jóvenes escolarizados asistentes a dos instituciones educativas de nivel secundario de la ciudad de Córdoba, una de gestión pública y otra privada, que estuvieran culminando el Ciclo Orientado ( $5^{\circ}$ año y luego $6^{\circ}$ año).

Asumiendo que los jóvenes ${ }^{4}$ tienen capacidad para reflexionar sobre sus experiencias personales e intersubjetivas y expresarlas discursivamente, reconstruimos sus sentidos escolares por medio de discursos generados en diversas actividades de indagación (escritas, observacionales, discusiones grupales, entrevistas profundas) que nos permitieran atender a la polifonía característica de los signos (Bajtín, 1990).

2 Verón (1993) detalla dos razones por las cuales no se puede analizar un discurso "en sí mismo": a) porque hay que ponerlo en relación con determinadas condiciones productivas; $\mathrm{y} b$ ) porque para hacer visibles las invariantes discursivas, relacionadas con condiciones de producción determinadas, deben compararse discursos sujetos a diferentes condiciones productivas.

3 Las condiciones sociofamiliares de vida y escolaridad fueron reconstruidas considerando las características generales de las escuelas (perfil, proyecto educativo, costo de la matrícula) y de la población educativa (trayectorias escolares de los jóvenes, condiciones residenciales, ocupación y nivel educativo de los progenitores, realización de trabajo juvenil). Estos datos fueron obtenidos por medio de informantes claves (preceptores de curso y secretarios), documentos y registros institucionales, hojas de datos personales y familiares que llenó cada joven participante de los grupos de discusión.

4 Sin desconocer las implicancias del sexismo lingüístico, para facilitar la lectura de este análisis utilizaremos "jóvenes" al referirnos en plural a los sujetos con los que trabajamos. 
Tabla 1. Condiciones vitales y escolares de producción de sentido.

Caso A

(13 jóvenes: 7 chicas y 6 varones)
Caso B

(17 jóvenes: 11 chicas y 6 varones)
Edades

Entre 17 y 21 años.

Barrio de la institución (4 jóvenes), asentamientos precarios (3) y barriadas cercanas (2), localidad aledaña (2), barrio a $15 \mathrm{~km}$ (2).

De gestión pública y gratuita, ubicada en la periferia de la ciudad. El nivel secundario tiene 450 estudiantes de sectores medios empobrecidos y asentamientos precarios. Funciona como "escuela recolectoEscuela ra” (Gallart, 2006) y de contención, recepta jóvenes expulsados y repitentes.

Varios docentes con doble cargo en la escuela (superposición de funciones), elevado ausentismo.

Apunta a la formación instrumental.

$48 \%$ de sobreedad, 5 repitieron (tres de ellos en 2 o más oportunidades).

\section{Trayectoria educativa}

Nivel educativo parental

Primario (50\%), secundario $(33,3 \%)$ y superior $(16,6 \%)$

Trabajos precarios: empleo doméstico, albañilería, changas $(43,47 \%)$. Trabajos en relación de dependenTrabajo pro-
genitores cia: empleados de comercio, militares, seguridad, docencia, enfermería $(30,43 \%)$. Autónomos: gráfica, almacén, bioquímica e inmobiliaria $(26,08 \%)$.

$53,85 \%$ trabajan (7 jóvenes): en actividades familiares (fábrica, gráfica, venta de empanadas), en una actividad aprendida en una práctica escolar (mozos en parrilla y salón de fiestas), en relación de dependencia (fast-food).
Entre 16 y 17 años.

Centro de la ciudad y barrios residenciales aledaños al colegio (12), barrios residenciales entre 4 y $9 \mathrm{~km}$ (5), localidades fuera de la capital (2).

De gestión privada y arancelada, cercana al centro de la ciudad. Tiene 360 estudiantes de nivel secundario de sectores mediosaltos

Selecciona al alumnado, prioriza a familiares de alumnos y exalumnos.

Funciona como espacio para "conservar las posiciones adquiridas" (Tiramonti, 2007).

Docentes con formación universitaria, perfil académico y experiencias de agremiación política.

Prioriza la formación propedéutica y político-ciudadana.

Edades escolares teóricamente esperadas, ninguno repitió.

Trayectorias escolares ininterrumpidas consonantes y correlativas a las de sus progenitores.

Ambos estudios superiores $(76,47 \%)$, uno con estudios secundarios completos y otro universitario (17,66\% - 3 jóvenes), ambos con secundario completo (5,88\% - 1 joven).

Desempeño de profesiones universitarias en relación de dependencia $(33,33 \%)$ o independiente $(45,45 \%)$. Con nivel secundario en relación de dependencia: asesor de seguros, congresista $(6,07 \%)$, cuentapropistas: taxistas, peluquera, amas de casa $(15,15 \%)$.

11,76\% jóvenes: disc-jockey (varón) y emprendimiento de indumentaria (mujer)

Fuente: Elaboración propia. 
Siguiendo una lógica comparativa, la información fue construida desde una estrategia de indagación múltiple implementada de forma análoga en ambos casos en estudio que fue diseñándose y ajustándose en virtud del análisis concomitante al trabajo de campo. Se desarrollaron tres etapas sucesivas en un proceso de focalización progresiva orientado a construir diferentes registros de las voces juveniles.

$\quad$ Primera etapa- Aproximación inicial:
observaciones de
recopilación $y$ jornadas escolares,
conversaciones informales con jóvenes $y$ adultos (directivos, preceptores y docentes), administración de una actividad escrita individual de "frases a completar" $80 \%$ del recorte juvenil precisado (99 de 123 jóvenes), construcción de núcleos de sentidos transversales que expresaban regularidades y diferencias en ambas poblaciones ${ }^{6}$.

Segunda etapa- Trabajo focalizado: grupos de discusión con el 24,4\% del recorte juvenil total de ambos casos ( 30 jóvenes de 123 total, 13 del caso A y 17 del caso B) con representación igualitaria de género y bajo criterios de muestreo que nos permitieron considerar diversas condiciones de significación al interior de una misma población juvenil. Construimos un guion único de discusión mediante el cual los invitamos a profundizar, en primer lugar, los núcleos de sentidos transversales construidos en la primera etapa, mayoritariamente valoraciones "positivas" sobre la escuela o que cuentan con amplia aceptación social. Luego, desde un planteo contra-argumentativo, les presentamos discursos que cuestionaban o contradecían tales valoraciones (datos de experiencias de investigaciones previas, estadísticos, observacionales, entre otros).

Tercera etapa: realizamos entrevistas biográficas con algunos de estos jóvenes cuando estaban finalizando sus estudios secundarios.

5 Estructurada en torno a tres ejes: 1) lo que significa para ellos la escuela; 2) los discursos de referentes significativos sobre la escuela secundaria (padres, docentes, amigos); 3) lo que imaginan les habrá dejado la secundaria para sus vidas futuras.

6 La escuela secundaria como: 1) "Base para tener un futuro mejor". 2) "Posibilidad para ser alguien en la vida". 3) "Base para conseguir trabajo digno". 4) "Preparación para estudios superiores". 5) "Espacio de sociabilidad". 6) "Espacio de formación personal y transición de la etapa adolescente".

\section{Aprender a vivir con otros: La secundaria como espacio-tiempo de sociabilidad}

Los jóvenes construyen diversas prácticas y relaciones de sociabilidad en los espacios que habitan, como la escuela, el barrio, la calle, las redes sociales de comunicación y otros lugares de encuentro o esparcimiento.

Los orígenes del concepto de sociabilidad se ubican en los desarrollos sociológicos de Simmel (2002) sobre las interacciones sociales. Bajo este concepto, el autor destaca la "forma lúdica de la asociación" (p. 197), que puede asumir distintas formas de asociatividad, pero todas "acompañadas de un sentimiento y una satisfacción en el puro hecho de que (...) la soledad del individuo se resuelve dentro de la unidad: la unión con otros" (p. 195).

Complementando la reactualización de significaciones históricas (sentidos instrumentales, aspiraciones de movilidad social ascendente, expectativas propedéuticas), el aprendizaje de la sociabilidad en la escuela secundaria se configura como una de las dimensiones de sentido de las experiencias escolares juveniles que se viene consolidando a partir de fines del siglo pasado. Desde la década de los noventa, diversas investigaciones socioeducativas han caracterizado a la escuela como un espacio de construcción de relaciones de diferentes connotaciones (compañerismo, amistad, enfrentamiento) y experiencias juveniles con características peculiares que suelen pasar desapercibidos a la mirada adulta o ser sancionadas cuando entran en confrontación con elementos propios de la cultura escolar (Dubet \& Martuccelli, 1998; Tenti-Fanfani, 2000; Weiss, 2012; Paulín, 2013; Dayrell \& Carrano, 2014).

Como desarrollaremos en los siguientes apartados, la posibilidad de relacionarse con otros en el espacio-tiempo de la secundaria adquiere diversos sentidos al interior de cada población juvenil con que trabajamos, vinculadas a las relaciones generacionales e intergeneracionales que allí establecen y de las que derivan diversos aprendizajes para sus vidas actuales y futuras. Para los jóvenes del primer caso, establecer relaciones en el cotidiano escolar los ayuda a comprender sus dificultades vitales y a gestionar solidariamente 
distintos riesgos que deban afrontar. Para los del segundo caso, la construcción de vínculos con sujetos con características sociales, culturales y económicas similares les garantiza continuidad de sus condiciones familiares de existencia.

\subsection{Aprendizajes para compartir y aliviar vivencias de dificultad (caso A)}

La secundaria es apreciada por estos jóvenes como espacio-tiempo relacional y comunicativo, por las posibilidades que allí tienen de aprender a tratarse, compartir, escuchar/se, expresar/se, respetar y hacerse respetar. De las relaciones y prácticas de sociabilidad que construyen en la escuela derivan aprendizajes que les posibilitan: construir relaciones intersubjetivas que trasciendan las del espacio barrial y tengan una referencia institucional, compartir vivencias de dificultad y trasladar conocimientos para futuros vínculos en el mundo laboral.

\subsubsection{Construir relaciones que} trasciendan la sociabilidad barrial. Para varios de estos jóvenes, escolarizarse aumenta las posibilidades de establecer relaciones de compañerismo y/o amistad respecto al espacio de sociabilidad barrial; vínculos que se prolongan en el tiempo por el tipo de vivencias compartidas. En palabras de uno de los jóvenes:

Rafael: "tengo amigos del barrio que tienen ya 25 años. $Y$ no hicieron el secundario y no tienen tantos amigos. (...) No salen nunca porque no tienen nadie para compartir para salir, nada... Entonces, están solos" (Fragmento de discusión, grupo $\mathrm{N}^{\mathrm{o}} 2$ ).

Investigaciones latinoamericanas enfatizan la posibilidad que brinda la escuela de ampliar los repertorios de sociabilidad al permitir desarrollar vínculos afectivos con pares y otros miembros de la escuela (Dos Santos et al., 2012), generar redes y grupos de confianza para construir sus experiencias escolares y sobrevivir en un medio inicialmente hostil (Cerda, Assaél, Ceballos \& Sepúlveda, 2000), tramitar dificultades y dilemas de la propia experiencia escolar (Foglino et al., 2008).

Para algunos jóvenes que, por su doble condición de estudiantes y trabajadores, ven acotadas sus prácticas de sociabilidad, el espacio-tiempo escolar es el único del que disponen para hacer amigos, como enfatizaba Rafael en un grupo de discusión: "Lo que pasa es que hay algunos que vienen al colegio y son compañeros después se van a su casa y están todo el día en el barrio. En cambio yo, menos barrio y más trabajo".

\subsubsection{Tener una "junta" con referencia} escolar. En su mirada, dentro y fuera de la escuela se conforman juntas "buenas" y "malas" que producen transformaciones subjetivas no deseadas ("cambian a la persona"). La secundaria se ofrece como un espacio que permite tener relaciones de compañerismo o amistad con referencia institucional, lo que tranquiliza a sus padres porque les acerca una idea de prácticas juveniles "no viciadas", como estar en la calle, no hacer nada, consumir drogas:

Viviana: "Tenés una cierta junta que tu mamá sabe que te juntás con los chicos que van al colegio (...) ella se queda tranquila porque dice 'bueno, van al colegio, son chicos buenos'. Porque si vos no vas al colegio a esta edad, ¿qué podés hacer? O te vas a trabajar o vivís en la calle. Hay pibes que no van al colegio y están todo el día al vicio. Y ahí donde agarran la droga, agarran todas esas cosas" (Fragmento de discusión, Grupo No 1).

En los discursos parentales que los jóvenes recuperaron, identificamos una recurrente alusión a permanecer en la escuela y finalizarla. Y si bien, a diferencia del caso B, no recuperaron referencias parentales acerca de disfrutar la dimensión juvenil de la escuela (amistades, etapa adolescente), de la exhortación a "sacar provecho" de estar escolarizados en lugar de trabajando se infiere una valoración de la vida escolar como refugio en un doble sentido: tanto físico y simbólico (como lugar que preserva de la calle y las "malas juntas"), como en términos de experiencia vital que conviene aprovechar ante un futuro que "puede ser peor".

\subsubsection{Aprender a compartir vivencias de}

7 En la jerga juvenil cordobesa, la "junta" alude a aquellos con quienes se pasa el tiempo compartiendo actividades, charlas y/o intereses comunes, en distintos espacios de sociabilidad (el barrio, la escuela, la calle). 
dificultad. Estos jóvenes valoran las relaciones con compañeros y amigos en la escuela porque les posibilitan construir aprendizajes al compartir similares experiencias de vida, intercambiar opiniones, entender y ponderar la importancia de las situaciones que viven, como problemas, dudas o tristezas:

Coordinadora: " $¿ \mathrm{Se}$ aprenden cosas de esas relaciones entre compañeros o amigos?"

Marcos: "Experiencias de vida (...) Cosas que ellos hayan vivido antes que te lo cuenten a vos".

Viviana: "O por ahí cosas que vos las ves muy graves y ellos te dicen 'no, no es tan asi"... Y es verdad, no es tan así".

Emiliano: "Están los amigos o compañeros para decir 'eh, mirá, me pasó esto, no sé, ¿vos que pensás? ¿O te pasó los mismo?' ¿entendés?"

Marcos: "Y te ayudan a liberarte un poco el lío en la cabeza".

(...)

Emiliano: "Momentos feos y momentos lindos".

Maira: "O por ahí los amigos te ayudan a despejarte de los problemas que tenés y te sentís bien con ellos, hablando".

Marcos: "O hablando con ellos te desahogás de algo que vos te bancás siempre sin contarle a nadie. Porque es tu amigo, le contás y te hace bien saber que otra persona te..."

Viviana: "Te escucha y te entiende".

(Fragmento de discusión, grupo $\mathrm{N}^{\mathrm{o}} 1$ )

Contarse situaciones vividas difíciles, consultarse acerca de cómo pensar o actuar frente a las mismas, compensar tensiones que atraviesan (en la familia, el trabajo, la pareja) son prácticas dialógicas que, producidas entre sujetos cuyas vivencias son similares, posibilitan cierta comprensión hermenéutica de la propia experiencia. Prácticas donde el lenguaje permite exteriorizar parte de la experiencia subjetiva (el sentido, no la vivencia como tal) tornándola experiencia social por medio de la acción comunicativa (Ricœur, 1999).

La importancia y particularidad de los intercambios dialógicos juveniles fue también enfatizado en investigaciones mexicanas sobre experiencias escolares. Para Reyes-Juárez (2009), el ámbito de esparcimiento y libertad que brinda la secundaria posibilita a los jóvenes un escape o desahogo de diversas situaciones que viven fuera de ella, como conflictos familiares, dificultades económicas o las cargas propias del trabajo. El abordaje de tópicos que en otros espacios (sus familias, la calle) se tornan difíciles de plantear, le permite a los jóvenes recibir comprensión, apoyo moral y afectivo de parte del grupo de amigos (GuerraRamírez, 2000), generar un espacio afectivo en el cual desahogarse de sus problemas y "anular la soledad"; en suma, conformar un "ámbito de tratamiento de los problemas juveniles" (Guerrero-Salinas, 2000, p. 28).

Estos jóvenes nominan "faltas de código" a las dificultades más comunes en sus relaciones en la escuela, como "ser falso" (cuando alguien cercano habla mal a espaldas de uno), "ser creído" o "forro" (quienes se creen superiores y descalifican a otros), "ser chusma" (práctica recurrente de "llevar y traer información"). Siendo la expresión de preocupaciones e inquietudes íntimas uno de los aspectos más valorados por ellos de la sociabilidad en la escuela, se comprende que estas "faltas de código" sean las menos toleradas de la convivencia intrageneracional pues se configuran en la antítesis del mostrarse auténticos.

3.1.4. Aprender a construir vínculos para el mundo laboral post-secundaria. Establecer relaciones de compañerismo y amistad en la secundaria se convierte para estos jóvenes en un aprendizaje para futuras prácticas de sociabilidad, principalmente el ámbito laboral:

Marcos: "Lo que te socializaste acá en el colegio te sirve también más tarde en tu trabajo. Socializarte con tus compañeros de trabajo, que algún día tengas algo, no sé, una cita con el médico. (...) Cuando te llevás bien, te cubre, te hace el aguante. Eso también sirve lo de socializarse".

Emiliano: "Claro, no solamente decir 'bueno, hago mi profesión, corto, me voy a mi casa'. No, te tomarás 5 minutos tomándote un café o un mate y charlás 
dos palabras con otros más, y ya ahí socializás".

Marcos: "Además para no sentirte solo en el trabajo, porque creo que si vos te sentís solo en el trabajo te aburrís, la pasás mal". Emiliano: "Claro, sos esclavo del trabajo!"

Maira: "Y no pasan más las horas para irte a tu casa!"

Marcos: "Si tenés un amigo te entretenés un poco más y no se te hace tan cansador y rutinario". (Fragmento de discusión, grupo $\mathrm{N}^{\mathrm{o}} 1$ )

Consideran que la construcción de relaciones de sociabilidad en el futuro ámbito laboral constituirá un plus para romper con la alternancia rutinaria casa-trabajo-casa, tolerar malestares de sobre-exigencias laborales y poder establecer intercambios solidarios entre pares ante dificultades que puedan presentarse.

Más allá de las dificultades específicas de la convivencia intrageneracional mencionadas, los sentidos juveniles sobre la sociabilidad trascienden los aspectos festivos, estéticos y lúdicos de un "vibrar juntos" (Weiss, 2012) . $^{8}$. Hipotetizamos que esto se deriva de las específicas condiciones juveniles de los sujetos con los que trabajamos, varios con situaciones difíciles de vida, la mayoría "sobrevivientes" a trayectorias escolares de dificultad y abandono, tanto parentales-familiares como congeneracionales.

Revisando estos sentidos a la luz de las condiciones de significación precisadas para este caso juvenil, el aprendizaje de la sociabilidad en la escuela se liga a dos aspectos centrales para sus existencias. Por una parte, con poder aliviar dificultades vitales al poder compartir vivencias similares y construir vínculos con "otros parecidos". Por otra, con poder afrontar riesgos tanto presentes (la escuela oficia como espacio-tiempo de "resguardo" ante dificultades y peligros inherentes a la sociabilidad barrial)

$8 \quad$ El autor critica la mirada de Maffesoli (1990) sobre las relaciones grupales, quien retoma el concepto de "sociabilidad" propuesto originalmente por Simmel (2002), pero enfatizando su realización en el presente, la necesidad de estar juntos por el simple hecho de estarlo y el predominio de excesos festivos dionisíacos. En las diversas investigaciones del equipo que dirige Weiss (2012), se subraya que si bien estos aspectos caracterizan buena parte de las relaciones juveniles, la convivencia cotidiana no se agota en ellos. como anticipados (por los aprendizajes que permitan contrarrestar dificultades en futuros espacios de sociabilidad como el laboral) ${ }^{9}$. Siguiendo a Hopenhayn (2004), este sentido de la sociabilidad como resguardo puede estar oficiando como estrategia ante el desamparo, vivencia inherente a las biografías de numerosos sujetos nacidos en los años 90' en Latinoamérica: "La misma sensación de precariedad obliga a conjurarla a través de un orden compartido en que se crea un imaginario de protección recíproca. Juntos, somos menos vulnerables" (p. 13).

En una solapada denuncia de situaciones de precariedad vividas o anticipadas como posibles, los sentidos asociados a la secundaria como espacio-tiempo de sociabilidad entre estos jóvenes se vinculan a aprendizajes que consideran cruciales para una gestión solidaria, colectiva e intergeneracional de los riesgos que pueden experimentar en sus vidas. Como manifestaba esta joven de 15 años en la actividad escrita de la primer etapa: "La escuela para mí es importante y terminarla es más importante (...) Me sirve en mi vida demasiado. Porque cuando pase el tiempo y no se me presente ninguna oportunidad en la vida voy a saber a quién recurrir, adonde ir, qué hacer, con quién debo estar acompañada y todo eso".

\subsection{Aprendizajes para perpetuar sus posiciones sociales (caso B)}

Los jóvenes de esta población estudiantil consideran que el espacio-tiempo de sociabilidad en la escuela es esencial porque posibilita establecer vínculos de amistad que permitan compartir y disfrutar la vida juvenil en el marco de una rutina escolar exigente; convivir con la alteridad en un ámbito que privilegia la homogeneidad; construir relaciones con referencia institucional y similitud socioeconómica y cultural; potenciar el valor de la palabra, la participación y expresión

9 Dos Santos et al. (2012) resaltan que jóvenes de sectores populares del noreste brasileño, a pesar que desean una escuela mejorada (infraestructura, organización, disciplina) con la cual poder identificarse y en la que se reconozcan sus necesidades e intereses, la consideran un soporte para enfrentar las dificultades de la vida y del mundo del trabajo. 
juvenil y aprender a relacionarse con otros para la futura vida universitaria.

\subsubsection{Construir lazos de amistad para} disfrutar la vida juvenil en el marco de una rutina escolar con elevadas exigencias. La escolaridad extendida, sumado a que la mayoría asiste allí desde el nivel primario, confluyen en la connotación afectiva de la secundaria como "el mejor lugar para hacer amigos y compañeros de la vida", "donde se crean los lazos más fuertes" y se "comparten vivencias" en común: Camila: "La secundaria, en sí, es el tiempo donde vos en realidad ves quiénes son tus amigos. Porque vivís tantas [énfasis en tantas] cosas juntos, y todos los días vivís las mismas cosas (...) Son las vivencias que vivís todos los días. Cómo te levantás a la mañana, lo que te pasó la noche anterior, o cosas así. Cómo te ayudan, además" (Fragmento de discusión, grupo $\mathrm{N}^{\mathrm{o}} 2$ ).

A diferencia de los jóvenes del caso A, estos jóvenes valoran las relaciones escolares en términos del "vibrar juntos" con el que Maffesoli (1990) conceptualiza la "socialidad": un disfrute hedonista y lúdico del presente entre quienes conforman un grupo de afines. En sus palabras, la secundaria es también "una segunda casa donde hacemos nuevas amistades y nos divertimos"10, "donde disfrutás el tiempo libre con tus amigos". Las relaciones juveniles son para ellos en buena parte significativas porque les permiten aliviar, no las dificultades de vida (como en el caso A), sino las exigencias propias de su escolaridad. En un marco institucional de intensas exigencias académicas (actividades contraturno, numerosas tareas para el hogar, lecciones y evaluaciones semanales), su escuela también aloja la sociabilidad juvenil posibilitando que diversos intereses juveniles (relacionales, recreativos, de participación) encuentran expresión en el seno de un mismo espacio y tiempo, el escolar. Como lo expresa esta joven en la actividad escrita individual: "Es un lugar donde disfruto venir a pesar de levantarme temprano y tener mil cosas que hacer, está bueno que podamos ayudar a la

10 Frases textuales de la actividad escrita individual.

Rev.latinoam.cienc.soc.niñez juv 15 (1): 101-115, 2017

http://revistalatinoamericanaumanizales.cinde.org.co

DOI:10.11600/1692715x.1510509112016 mente a desarrollarse, tener nuevas experiencias de las clases y sobre todo estar con los amigos, no fuera de la escuela, sino adentro".

\subsubsection{Convivir con la alteridad en un} ámbito que privilegia la homogeneidad. El "encuentro con los otros diferentes" es considerado por estos jóvenes como un aspecto nodal de la sociabilidad escolar que posibilita y enriquece la formación personal. Sin embargo, algunos parecen advertir que, en el contexto de cierta homogeneidad socioeconómica y cultural característica de la población estudiantil que asiste a su colegio, las diferencias son más aparentes que reales:

Alejandro: "[en este colegio] se acepta al diferente. Se acepta que el otro piense diferente a vos y se lo toma, ¿entendés? O sea, vos pensás diferente y lo podés plantear y te escuchan".

(...)

Andrea: "Lo que vos decís de que son diferencias en cuanto a cómo pensamos (...) acá me parece que hay diferencias pero no es la brecha que puede haber en el * [colegio público preuniversitario]. Acá hay que pagar una cuota. Por eso a lo mejor no es tan grande esa brecha de.... de las clases sociales donde cada uno está".

(Fragmentos de discusión, grupo $\mathrm{N}^{\mathrm{o}} 2$ )

Mariana: "Lo rico para mí es eso. La posibilidad que te da en algún punto de poder construir desde las diferencias... Que en realidad es una posibilidad, pero también está acotada a su vez por el colegio. Porque (...) no tenemos mente distinta en muchas cuestiones".

Sabrina: [Acota] "No tenés tantas diferencias" (Fragmentos de discusión, grupo 3).

\subsubsection{Construir relaciones con referencia} institucional y similitud socioeconómica y cultural. Resaltan que con sus compañeros del colegio tienen más vivencias en común que con amigos del barrio puesto que, al poder compartir con los primeros su cotidianeidad, van encontrando entre sí mayores "semejanzas de gustos y objetivos", que es lo que lleva a 
"sentirse amigos". Poder compartir, dentro de un mismo ámbito institucional, similares modos de vivir y ser joven adquiere relevancia en la construcción de las amistades juveniles escolares que devienen, para ellos, en "los lazos más fuertes" y "verdaderos", aquellos que tienen en común condiciones similares de vida: Martín: "Yo creo que las amistades más fuertes capaz son las que se viven en el colegio porque más o menos las realidades son las mismas. Y no así con las amistades que uno puede llegar a tener en el barrio que ahí sí, pueden, qué sé yo... Capaz que cuando sos más chico lo único que te importa es ir a jugar al fútbol todos los días, entonces la amistad puede ser constante, todo el verano juntos, todo el año juntos. Pero ya cuando vas creciendo se van buscando otros aspectos de las personas..." (Fragmento de discusión, Grupo $\mathrm{N}^{\mathrm{o}} 2$ ).

El tipo de relaciones posibles de establecer con congéneres y adultos con determinado perfil gravita en la elección institucional de estas familias pertenecientes a sectores medios-altos: "[Mis padres] No sólo eligieron mi escuela para que aprenda, sino también por el grupo humano que se encuentra en la institución", ilustraba una joven de 16 años en la actividad escrita individual de "frases a completar". Como señala Núñez (2014), la búsqueda de escenarios de socialización y sociabilidad homogénea, a imagen y semejanza de las familias, expresa y profundiza tanto la fragmentación escolar como la construcción de ofertas educativas segmentadas en calidad.

Algunos de los aprendizajes reseñados hasta aquí, derivados del tipo de sociabilidad que posibilita la escuela constituirían el fundamento último de la elección educativa que realizan sus padres:

Sabrina: "La persona que me trata de formar mi colegio no es la misma que en otros colegios. Y justamente, mis viejos sabían a qué colegio me estaban mandando y a qué clase de persona me querían direccionar".

Verónica: "Eso! Depende del colegio, de la persona y también de su familia. (...) No significa que porque todos vengamos a este colegio vamos a salir pensando igual o con el mismo tipo de personalidad, para nada!"’.

Valeria: "Al contrario, pero creo que te forma en ciertos valores".

(...)

Sabrina: "Es que creo que justamente por eso se eligen ciertos colegios y ciertos no. Mis viejos (...) como que analizan que este colegio tiene una educación de los pares, el tipo de... por ahí nivel social con el que quieren que yo me... no suena muy bien, suena mal... pero con quiénes quieren que me relacione. Como que es el colegio más balanceado: que tiene la educación del tipo el profesor tal, que te va a enseñar bien matemática, lengua' y también como la relación con la gente".

(Fragmentos de discusión, grupo $\mathrm{N}^{\mathrm{o}} 3$ ).

La elección y el control de la sociabilidad de sus hijos es una estrategia de familias de élite que procura una pertenencia grupal referencial que a futuro les permita mantener sus posiciones privilegiadas (Tiramonti, 2007). Poder establecer relaciones con jóvenes socialmente similares, junto a la organización de un mundo escolar afín al familiar, la provisión de una fuerte pertenencia institucional (a través de jornadas escolares extendidas y diversas actividades extracurriculares) y una formación académica rigurosa son estrategias familiares y educativas selectivas que les garantizan una reproducción del habitus o patrones de clase no azarosa (Ziegler, 2007). Nos interesa destacar, para el caso analizado, la presencia de una conciencia reflexiva en los jóvenes sobre esta selectividad parental de sus lazos y prácticas de sociabilidad.

3.2.4. Potenciar el valor de la palabra, la expresión y participación juvenil. Otra de las características destacadas por estos jóvenes es la posibilidad de intercambiar miradas y opiniones, argumentar puntos de vista, discutir, plantear inquietudes y quejas, realizar propuestas y resolver problemas con quienes comparten su cotidianeidad.

Camila: "Lo que tiene este cole es que nuestra opinión vale mucho. $\mathrm{O}$ sea, nosotros podemos... quejarnos, no sé si sería la palabra. Pero podemos proponer y hacer un montón de cosas". 
Gimena: "Claro, eso abre a muchas opiniones, cosas así que te relacionan con otros"

Coordinadora: "Para ustedes, ¿eso incide en las relaciones que pueden establecer entre ustedes?"

Andrea: "Para mí sí. (...) como que te vas acostumbrando a lo que pasa en la vida, digamos, te vas a encontrar con gente con la que no te vas a llevar bien y que te vas a tener que llevar igual, por ejemplo, en un trabajo. Pasa en el cole también".

(...)

Joaquín: "Sí, la opinión de uno, lo que es relacionarse con los otros. Lo que no lo tienen las materias, uno aprende a dialogar con otros, a formarse uno mismo en espacios de debate y terminás siempre relacionándote con todos"

[Hablan varios a la vezy ríen] (Fragmentos de discusión, grupo $\mathrm{N}^{\mathrm{o}} 2$ ).

El lugar que en su escuela le otorgan a la palabra y la participación juvenil les posibilita derivar aprendizajes dialógicos que gravitan no sólo en sus relaciones de sociabilidad, sino en la construcción de un posicionamiento como ciudadanos críticos y participativos ${ }^{11}$.

\subsubsection{Aprender a relacionarse con otros} para la futura vida universitaria. Un aspecto indicado por los jóvenes como esencial de las prácticas y experiencias de sociabilidad escolar es la preparación para el mundo relacional postsecundaria. Consultados acerca de aquellos aspectos que consideran su colegio enfatiza, señalan:

Andrea: "Para mí aprender a relacionarse con otras personas. Que es necesario porque vivimos en una sociedad $y$ necesitamos relacionarnos con las personas. Y eso también se relaciona con el trabajo, con..."

Martín: "Es que esas vivencias y esos valores que vos podés llegar a aprender, van a estar presentes en todo momento

11 El valor que su escuela otorga a las voces juveniles y los espacios de participación les posibilitan sucesivas prácticas y experiencias en las que defender sus convicciones, plantear sus necesidades, reivindicar sus derechos y aprender a tomar decisiones para la vida en otros espacios institucionales (D’Aloisio, 2015). de tu vida, en todo ámbito, no solamente en la escuela, sino también cuando estés en la facultad, o para relacionarte en un trabajo con tus compañeros"

Camila: “(...) Principalmente, la secundaria está para eso. Para enseñarte cómo te vas a relacionar después, cómo vas a actuar en distintos hechos $\mathrm{y}$, bueno, principalmente para que eso te abra la puerta a una universidad o a tener un título en el futuro" (Fragmentos de discusión, grupo $\mathrm{N}^{\circ} 2$ ).

Valoran especialmente estos aprendizajes relacionales por considerar que gravitan en el modo en que se relacionarán con otros en sus futuros estudios universitarios o en el espacio laboral; incluso, consideran que pueden facilitarles el desempeño en esos ámbitos. Relacionarse con pares y adultos en un contexto de exigencia académica, construir relaciones de compañerismo y amistad, poder intercambiar diversas opiniones, discutir y argumentar ideas, son señaladas por estos jóvenes como prácticas dialógicas que posibilita la escuela secundaria (y su colegio de modo específico) en tanto espacio-tiempo de sociabilidad homogénea que guarda estrecha similitud al ámbito familiar. De estas prácticas y experiencias derivan aprendizajes sustanciales para sus procesos de subjetivación y proyecciones a futuro, como el garantizar un desempeño adecuado en la vida universitaria y perpetuar sus actuales condiciones de existencia.

\section{Comentarios finales}

Junto a una reactualización de significados sociohistóricos, la sociabilidad juvenil en la escuela secundaria se configura como un campo de sentidos que viene siendo señalado por numerosas investigaciones de las últimas décadas tanto en nuestro país (Maldonado, 2000, Kessler, 2002, Dussel et al., 2007, Foglino et al., 2008, Llinás, 2009, Paulín, 2013) como en otros países latinoamericanos (Dayrell, 2007, Cerda et al., 2000, Guerra-Ramírez, 2000, Guerrero-Salinas, 2000, Hernández-González, 2008, Reyes-Juárez, 2009, Weiss, 2009, 2012, Dos Santos et al., 2012, Guerra-Ramírez \& Guerrero-Salinas, 2012). 
El análisis de los sentidos reseñados en ambas poblaciones juveniles nos permite señalar, siguiendo a Weiss (2012), que las relaciones de sociabilidad intrageneracional en el espacio-tiempo escolar, aunque puedan incluirlo, exceden el mero divertirse y se constituyen en oportunidades de aprendizajes diversos y relevantes para sus vidas actuales y futuras. Como plantean Dayrell y Carrano (2014), es posible comprender las prácticas y relaciones de sociabilidad juvenil como respuestas a sus necesidades de comunicación, de intercambios afectivos, de solidaridad, autonomía y construcción identitaria.

Revisando el análisis desplegado a la luz del planteo de Simmel (2002), las relaciones de sociabilidad juvenil en ambos casos no parecen cumplir con los criterios con que el autor las caracterizaba: la no intervención de aspectos que dieran cuenta de la importancia objetiva de la personalidad (riquezas, posición social, instrucción, méritos del individuo), o sólo se expresaran como matiz, ni las cualidades profundamente personales e íntimas (el humor o el carácter). Considerando los sentidos juveniles del caso A, en las relaciones de sociabilidad que construyen en la escuela no quedan por fuera las cualidades más íntimas y personales sino que, por el contrario, poder expresarlas y compartirlas constituye un aspecto nodal de esos vínculos. Mientras que, en la mirada juvenil del caso B, las cualidades objetivas (condiciones juveniles-familiares) lejos de quedar por fuera, son origen y fundamento de las relaciones de amistad en el ámbito escolar, consideradas por ellos las más "genuinas", "duraderas" y que cuentan con aprobación familiar.

Las voces juveniles analizadas expresan valoraciones de sus escuelas por los encuentros e intercambios dialógicos que permite con otros similares, configurándose de esta manera una marcada homogeneidad interna y una creciente distancia social entre poblaciones congeneracionales disímiles (Núñez, 2014).

Como intentamos mostrar, la secundaria en tanto espacio-tiempo de sociabilidad se vincula a vivencias y prácticas situadas que van dando cuerpo a distintos aprendizajes, como poder construir relaciones con otros semejantes a sí mismos con quienes compartir experiencias, distenderse y aliviar dificultades vitales (caso A) o disfrutar la etapa que transitan en un marco similar al familiar y de elevadas exigencias académicas (caso B). Pero también construyen herramientas potenciales para la vida ulterior: saber relacionarse con otros supone un aprendizaje central para desenvolverse en futuros ámbitos laborales (caso A) o formativo-profesionales (caso B). La preeminencia de este orden de sentidos entre los jóvenes de sectores populares como el primer caso puede ser entendida, en parte, como efecto de la pérdida del monopolio cultural propia del dispositivo escolar; por otra, como protección ante la "inconsistencia posicional" característica de los procesos de subjetivación contemporáneos: la posibilidad de construir vínculos parece aumentar la certidumbre de poder contar con la ayuda de otros (Araujo \& Martuccelli, 2012) para afrontar dificultades, compensar malestares y establecer intercambios solidarios en un marco de horizontalidad. La valoración de la sociabilidad entre los jóvenes de sectores medios-altos como el del segundo caso se vincula a la posibilidad de asemejar las prácticas y vínculos escolares a las del ámbito familiar así como capitalizar estrategias para sostener a futuro sus actuales condiciones de existencia.

Las apreciaciones analizadas sobre los vínculos y prácticas de sociabilidad revelan así que la escuela secundaria tiene un papel importante en los procesos de subjetivación juvenil, cuestión que viene siendo enfatizada por diversos cientistas sociales (Dubet \& Martuccelli, 1998, Hernández-González, 2008, Weiss, 2009, 2012, Molina-Chávez, 2014, Paulín \& Tomasini, 2014).

La identificación de estos sentidos en poblaciones juveniles cuyas condiciones de vida y escolarización difieren de modo notable nos permite enfatizar que la escuela secundaria, junto a la familia, el trabajo o nuevos estudios, sigue teniendo relevancia como espacio de construcción de sujetos sociales.

Centrándonos en los sentidos analizados en este artículo, para unos jóvenes la sociabilidad en el espacio-tiempo escolar les posibilita, 
con ayuda de sujetos con vivencias similares, hacer frente a diversas dificultades estructurales que atraviesan en sus vidas (precariedad, explotación laboral, entre otros). Esto no implica necesariamente una modificación de sus condiciones de existencia, sino una forma de tolerar y manejarse con la incertidumbre y riesgos inherentes a sus devenires y porvenires biográficos. Los otros jóvenes, que construyen sus prácticas de sociabilidad en un escenario escolar de marcada homogeneidad, sin mayores contactos con jóvenes de otros sectores socioeconómicos y culturales, se aseguran una reproducción estamentalizada de sus posiciones sociales (Chaves, 2010). Esto nos permite señalar que la escuela secundaria parece seguir jugando un papel clave en la producción de subjetividades que sostienen determinado orden social.

\section{Lista de referencias}

Alonso, L. E. (2013). “La sociohermenéutica como programa de investigación en sociología". Arbor, 189 (761): a035, pp. 1-15.

Doi: $\quad$ http://dx.doi.org/10.3989/ arbor.2013.761n3003.

Andrade-Glória, D. M. (2003). A "escola dos que passam sem saber": A prática da nãoretenção escolar na narrativa de alunos e familiares. Revista Brasileira de Educação, 22, pp. 61-76.

Araujo, K. \& Martuccelli, D. (2012). Desafíos comunes: Retrato de la sociedad chilena y sus individuos. Santiago de Chile: LOM.

Bajtin, M. M. (1990). Estética de la creación verbal. México, D. F.: Siglo XXI.

Cerda, A. M., Assaél, J., Ceballos, F. \& Sepúlveda, R. (2000). Joven y alumno: ¿Conflicto de identidad? Un estudio etnográfico en liceos de sector popular. Santiago de Chile: LOM-Piie.

Chaves, M. (2010). Jóvenes, territorios y complicidades. Una antropología de la juventud urbana. Buenos Aires: Espacio Editorial.

D’Aloisio, F. (2015). Escuela secundaria como formación personal para la vida ulterior:
Dignidad, éxito y ciudadanía. Un análisis comparativo de significaciones juveniles situadas en condiciones disímiles de vida y escolaridad. Revista Mexicana de Investigación Educativa, $X X$ (67), $p p$. 1131-1155.

Dayrell, J. (2007). A escola 'faz' as juventudes? Reflexões em torno da socialização juvenil. Revista Educação \& Sociedade, 28 (100), pp. 1105-1128.

Dayrell, J. T. \& Carrano, P. (2014). Juventude e ensino médio: Quem é este aluno que chega à escola. En J. Dayrell, P. Carrano \& M. Linhares (org.) Juventude e ensino médio sujeitos e currículos em diálogo, (pp. 101133). Belo Horizonte: Editora UFMG.

Del Cueto, C. M. (2007). Los únicos privilegiados: Estrategias educativas de familias residentes en countries y en barrios cerrados. Buenos Aires: Prometeo Libros, UNGS.

Dos Santos, R. M., Nascimento, M. A. \& Menezes, J. de A. (2012). "Os sentidos da escola pública para jovens pobres da cidade do Recife". Revista Latinoamericana de Ciencias Sociales, Niñez y Juventud, 10 (1), pp. 289-300.

Dubet, F. \& Martuccelli, D. (1998). En la escuela. Sociología de la experiencia escolar. Barcelona: Losada.

Duschatzky, S. \& Corea, C. (2007). Chicos en banda. Los caminos de la subjetividad en el declive de las instituciones. Buenos Aires: Paidós.

Dussel, I. Brito, A. \& Núñez, P. (2007). Más allá de la crisis: Visión de alumnos y profesores de la escuela secundaria argentina. Buenos Aires: Santillana.

Foglino, A. M., Falconi, O. \& López-Molina, E. (2008). Una aproximación a la construcción de la experiencia escolar de adolescentes y jóvenes de grupos sociales urbanos en condiciones de pobreza en Córdoba. Cuadernos de Educación, VI (6), pp. 227-243.

Gadamer, H. G. (1992). Verdad y Método II. Salamanca: Sígueme.

Gallart, N. (2006). La construcción social de la escuela media. Una aproximación institucional. Buenos Aires: La Crujía. 
Ghiardo-Soto, F. \& Dávila-León, O. (2005). Cursos y discursos escolares en las trayectorias juveniles. Última Década, (23), pp. 33-76.

Guerra-Ramírez, M. I. (2000) ¿Qué significa estudiar el bachillerato? La perspectiva de los jóvenes en diferentes contextos socioculturales. Revista Mexicana de Investigación Educativa, 5 (10), pp. 243272.

Guerra-Ramírez, M. I. \& Guerrero-Salinas, M. E. (2012). ¿Para qué ir a la escuela? Los significados que los jóvenes atribuyen a los estudios de bachillerato. En E. Weiss (coord.) Jóvenes y bachillerato, (33-62). México, D. F.: Anuies.

Guerrero-Salinas, M. E. (2000). La escuela como espacio de vida juvenil. Dimensiones de un espacio de formación, participación y expresión de los jóvenes. Revista Mexicana de Investigación Educativa, 5 (10), pp. 205-242.

Hernández-González, J. (2008). El trabajo sobre la identidad en los jóvenes de bachillerato: Reflexividad, voces y marcos morales. México, D. F.: Universidad Pedagógica Nacional.

Hopenhayn, M. (2004). Desamparo y exclusión social en América Latina. En M. A. Antonelli (comp.) Cartografias de la Argentina de los '90. Cultura mediática, politica y sociedad, (13-36). Córdoba: Ferreyra Editor.

Kessler, G. (2002). La experiencia escolar fragmentada. Estudiantes y docentes en la escuela media en Buenos Aires. Buenos Aires: Iipe, Unesco.

Llinás, P. (2009). Imágenes y sentidos de la experiencia escolar: Percepciones de los estudiantes sobre la escuela secundaria. Revista Propuesta Educativa, 32, pp. 95104.

Maffesoli, M. (1990). El tiempo de las tribus. Barcelona: Icaria.

Maldonado, M. M. (2000). Una escuela dentro de una escuela. Un enfoque antropológico sobre los estudiantes secundarios en una escuela pública de los '90. Buenos Aires: Eudeba.
Meo, A. \& Dabenigno, V. (2010). Expansión de las aspiraciones educativas en jóvenes de sectores populares. ¿Evidencias de la emergencia de un nuevo habitus escolar en la Ciudad de Buenos Aires? Revista Iberoamericana de Educación, 53 (5), pp. 1-13.

Molina-Chávez, W. M. (2014). Configuración de sentidos y subjetividades sobre los procesos de escolarización secundaria desde la experiencia de estudiantes de liceos públicos municipales en Chile. En F. Saforcada y H. F. Ospina (comps.) Emergencias educativas, ciudadanas $y$ democráticas en Chile y Colombia, (247303). Buenos Aires: Clacso.

Núñez, P. (2014) La construcción de ciudadanía en la escuela secundaria: Convivencia, regulación de la participación juvenil y nuevas dinámicas de desigualdad. Revista de la Escuela de Ciencias de la Educación, 10 (9), pp. 35-52.

Paulín, H. (2013). Conflictos en la sociabilidad entre jóvenes. Un estudio psicosocial sobre las perspectivas de estudiantes y educadores de escuelas. Tesis inédita de Doctorado. Facultad de Psicología, Universidad Nacional de Córdoba, Córdoba, Argentina.

Paulín \& Tomasini (2014). Jóvenes y escuelas. Relatos sobre una relación compleja. Córdoba: Brujas.

Reyes-Juárez, A. (2009). La escuela secundaria como espacio de construcción de identidades juveniles. Revista Mexicana de Investigación Educativa, 14 (40), pp. 147174.

Ricoeur, P. (1999). Teoría de la interpretación. Discurso y excedente de sentido. México, D. F.: Siglo XXI.

Simmel, G. (2002). Sobre la Individualidad y las formas sociales. Escritos Escogidos. Buenos Aires: Universidad Nacional de Quilmes.

Tapia-García, G. (2012). Perspectivas de los "nuevos estudiantes" al ingresar al bachillerato en el Bajío mexicano. En E. Weiss (coord.) Jóvenes y bachillerato, (6395). México, D. F.: Anuies. 
Tenti-Fanfani, E. (2000). Culturas juveniles y cultura escolar. Buenos Aires: Iiepe.

Tenti-Fanfani, E. (2007). La escuela y la cuestión social. Ensayos de sociología de la educación. Buenos Aires: Siglo XIX.

Thompson, J. B. (1993). Ideología y cultura moderna. Teoría crítica social en la era de la comunicación de masas. México, D. F.: UAM-X.

Tiramonti, G. (2007). La trama de las desigualdades educativas: Mutaciones recientes en la escuela media. Buenos Aires: Manantial.

Verón,E.(1993).La semiosis social. Fragmentos de una teoría de la discursividad. Barcelona: Gedisa.

Weiss, E. (2009). Jóvenes y bachillerato en México: El proceso de subjetivación, el encuentro con otros y la reflexividad. Propuesta Educativa, (32), pp. 83-94.

Weiss, E. (2012). Jóvenes y bachillerato. México, D. F.: Anuies.

Ziegler, S. (2007). La escolarización de las élites: Un acercamiento a la socialización de los jóvenes de sectores favorecidos en la Argentina actual. En G. Tiramonti (comp.) La trama de las desigualdades educativas: Mutaciones recientes en la escuela media, (73-99). Buenos Aires: Manantial. 